\title{
IOT BASED SMART SOLAR STREET LIGHT BATTERY/PANEL FAULT DETECTION
}

\author{
Omprakash Singh, Rucha Deshpande, Pranali Ikhar, Manish Hedaoo, Prof Yogita Nafde \\ Department of Electronics \& Telecommunication Engineering \\ Priyadarshini College of Engineering, Nagpur, Maharashtra, India.
}

\begin{abstract}
The internet of things (IoT) is able to implement transparently a very large amount of heterogenous end systems, while digital service provides an open access to sub set of data. The focus of this paper is to design \& analyze a technologically advanced, cost effective smart solar street light which will detect the faults in the street light's battery/panel with the use of PHP (Hypertext Preprocessor) \& the microcontroller ESP32. Now a days, Street lights have become a vital aspect including road safety. But the major problem of today in street lights is that the solar street light with sensors need to be equipped with solar cells and solar panels, this has become the target of the theft or criminals. Apart from this, battery theft or fault is also a major challenge facing the operation of installed power infrastructure. It has caused many of such system to be nonfunctional. This paper present a theft or fault detection system for protecting solar street lighting infrastructure. To solve this problem, continuous monitoring of the solar and battery voltage needs to be done. This data can be fetched over the server using server scripting language i.e. PHP. When someone try to remove the battery or solar panel, it will be displayed on the website. The monitored data with date and time can be retrieved as a tabular data for future analysis. With the implementation of this work, precautionary alerts can be given to the service department on the designed website. Arduino Uno module is employed as the main controller of the system. A relay is employed to switch ON and OFF the LED. The prototype is designed and found excellent results.
\end{abstract}

Keywords:--Arduino Uno Controller, Wifi Module i.e. Node MCU, ESP32 microcontroller.

\section{INTRODUCTION}

Street lights are the elemental part of any city since it facilitates better night visions, secure roads, and exposure to public areas but it consumes a quite large proportion of electricity. Also now a days, there is a risk that the battery or solar panel may get damaged or stolen. Due to this, the street light remains OFF for particular time period till the maintenance team comes and repair or restores the fault. Also, in manual streetlight system lights are powered from sunset to sunrise with maximum intensity even when there is sufficient light available. This energy wastage can be avoided by switching off lights automatically $[1,2]$. The saved energy can be efficiently utilized for other purposes like residential, commercial, transportation etc. In case of battery or solar panel fault, the service department is unable to recognize the fault or steal due to lack of information and unawareness, so the particular street light remains off for very long time [5]. Because of this, due to darkness accidents may occur [1]. IoT is the network of physical devices that allows the devices to communicate with each other. These system allows greater transparency, control and good performance.

Automation simplifies various problems in the world economy as well as in daily life. It uses the latest technology in LED as the light source to restore conventional street lamps. The LED lights are adapted because of its various advantages over existing technologies like power saving due to increased current luminous efficiency, reduced maintainance cost, high colour rendering index, and durability [8]. Nowadays flexibility of street lights system is being highly challenged. Handling remote area location is the greatest dilemma. Here, relay is used as the automatic switch and reduce almost $100 \%$ of manual work $[2,6]$. The main issue of existing electric system is the connectivity problem as most of the connections handled by different contractor are done manually. It supports client server mechanism where a single user can control the overall system [5]. Arduino is an open source microcontroller which is used with other communication technologies [3]. 
ESP32 is a low cost Wi-Fi modules with an AT commands library. It allows the arduino to connect to the internet through Wi-Fi connection [7]. Arduino collects all the data uploaded from sensors and transmits it to the cloud server by using Wi-Fi module ESP32, which is mounted on arduino through on board serial port.

The data on the cloud server will be displayed location wise. The designed website will be hosted on the same cloud using PHP programming language. Website will contain the separate dashboards and news, surveys related to the solar and battery voltage [1]. The website link will be provided on the college website. In this paper, we will present a system for monitoring the battery/solar voltage or if in case, it get removed, then an SMS will be generated and sent to the provided mobile number [4]. The outline of the paper is as follows.

\section{PROPOSED ALGORITHM:}

\section{MATERIALS \& METHODS}

The objective of this paper is to design and implement a system for detecting the fault in the battery or solar panel \& provide theft detection using Internet of Things (IoT) as well as conservation of energy by reducing electricity wastage. The model initiates sensor devices that can sense, compute \& communicate data in a network. Monitored data is wirelessly transmitted via Wi-Fi module to the server.

The block diagram of the system is shown below:

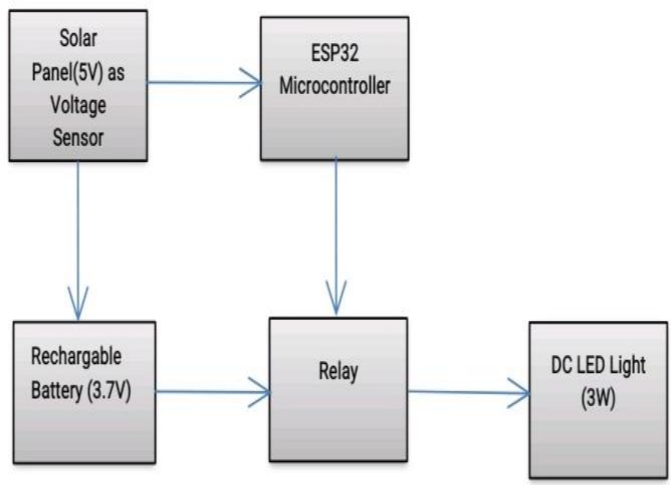

Fig.1 Block Diagram
Flow chart of the system is shown below:

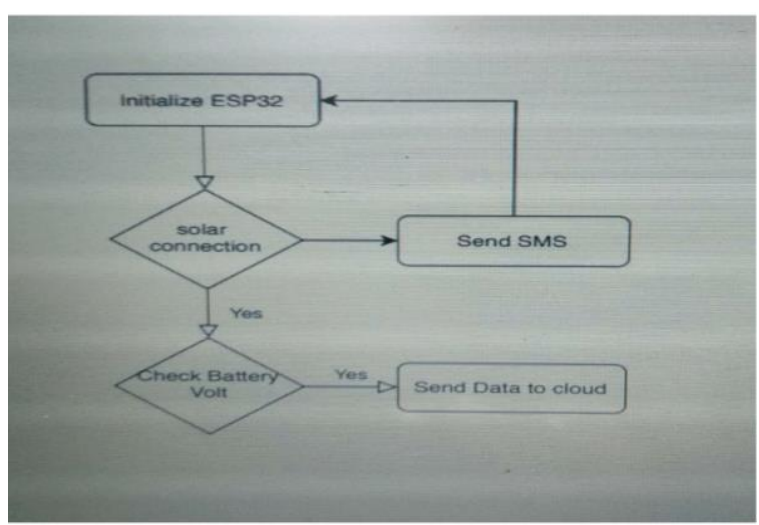

Fig.2 Flow Chart

Schematic diagram of the system is shown below:

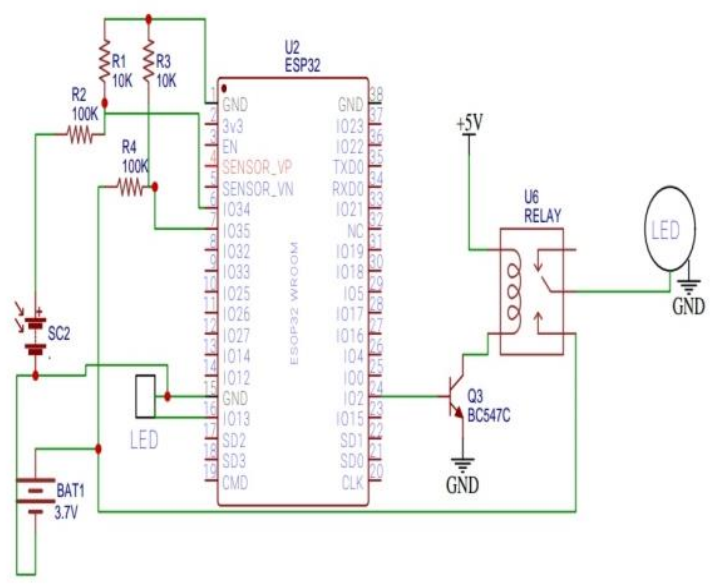

Fig.3 Schematic Diagram

The hardware requirement is presented in the next Section.

\section{HARDWARE EQUIPMENT}

\section{Arduino:}

Arduino software is used in this project. This software makes it easy to write code and upload it to the board. It runs on Linux Mac, Windows, Os and X. The software is written in Java and is based on processing and other open source software. It can be used with any Arduino board. 


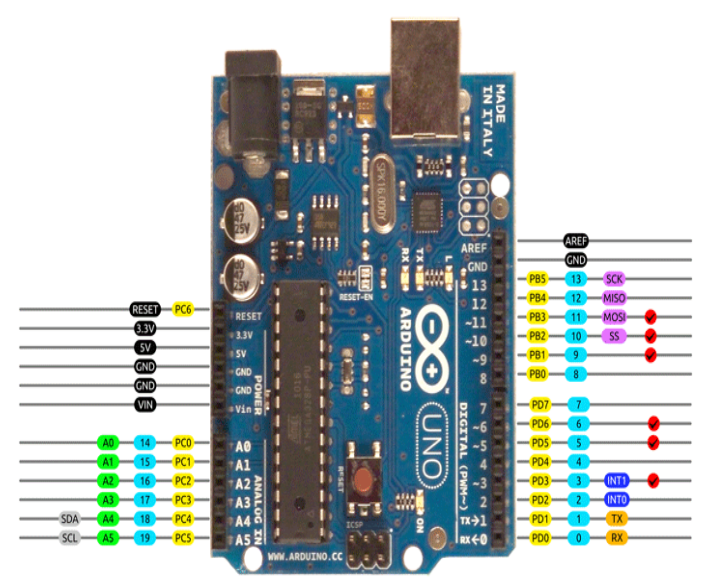

AVR DIGITAL ANALOG POWER SERIAL SPI I2C PWM INTERRUPT

The Arduino board is able to read the inputs such as finger on a button, output such as activating motor or turning on an LED, etc. We can tell the board what to do by sending a set of instructions to the microcontroller on the board. Arduino boards are inexpensive as compared to other microcontroller platforms. The program in this software is written in embedded $\mathrm{C}$ language.

\section{ESP32 Microcontroller:}

The ESP32 is a series of low cost, low power system on chip microcontrollers with integrated Wi-Fi and dual mode Bluetooth capabilities. The ESP32 series employs a Tensilica Xtensa LX6 microprocessor in both dual core and single core variations. Processor, operating at 160 or $240 \mathrm{MHz}$ and performing at up to 600 DMIPS.

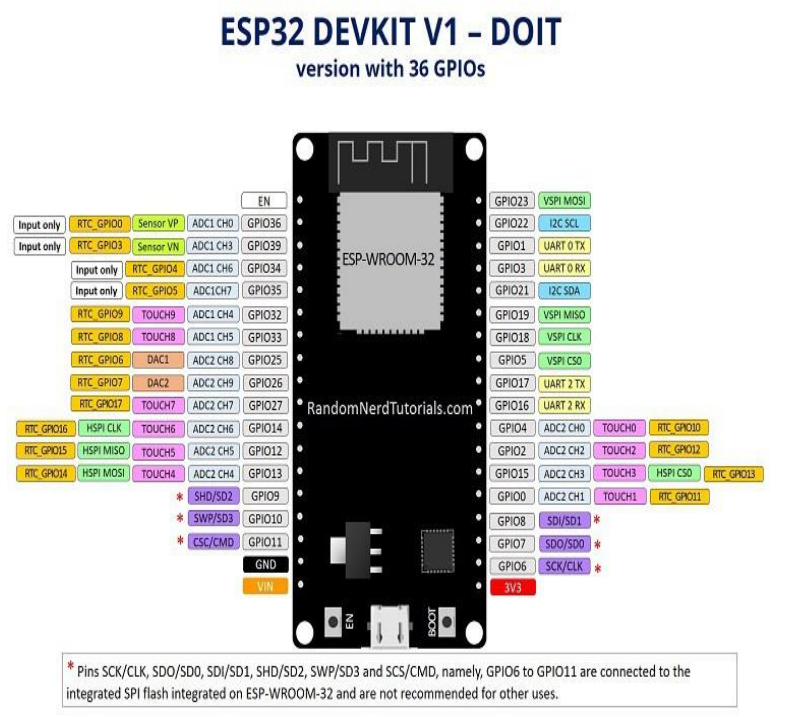

It is mounted on the Arduino board to get connected to the internet using WiFi connection.

\section{Node MCU:}

Node $\mathrm{Mcu}$ is an open source development board. It allows to program the WiFi module with Arduino IDE. Writing just a few lines of code, we can establish a WiFi connection and input/output pins can be defined according to our need like arduino, turning WiFi module into a web server, etc.

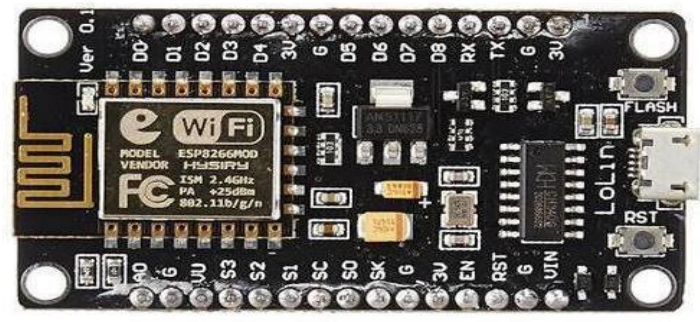

It can be programmed with the Lua programming language or Arduino IDE. WiFi networking, connectivity to the internet or fetching or uploading the data can be done here.

\section{Solar Panel:}

Solar panels are made up of solar cells which converts the sunlight into electricity. They are also known as photo voltaic solar module. Solar cells are made from silicon. There are several types of solar panel. They are,

- Polycrystalline Solar Panel

- Monocrystalline Solar Panel

- Thin Film Solar Panel

Out of these three only polyscrystalline and monocrystalline solar panel are widely used for home solar system and commercial solar system.

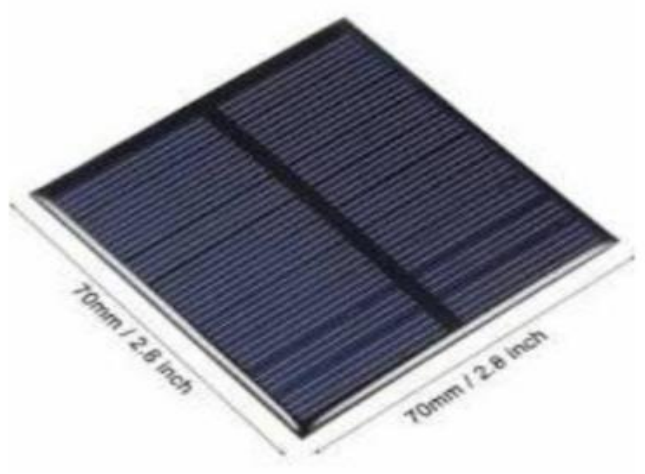


Solar Panels are widely used in street lights now a days. These makes the street lights advance and reduces the electricity wastage. In this project, solar panel is connected in the circuit and programmed in such a way that if light is obtained on the panel, the status of the solar becomes ' 0 ' and hence LED remains OFF. In the same way, if we keep hand on the panel i.e. if we cover the panel, light will not be obtained on the panel which seems the night time and hence the LED will glow sending the solar status as '1' on the system.

\section{Relay:}

Relays are switches that open and close circuits electromechanically or electronically. Relays control one electrical circuit by opening and closing contacts in another circuit. When a relay contact is normally open, there is an open contact when the relay is not energized.

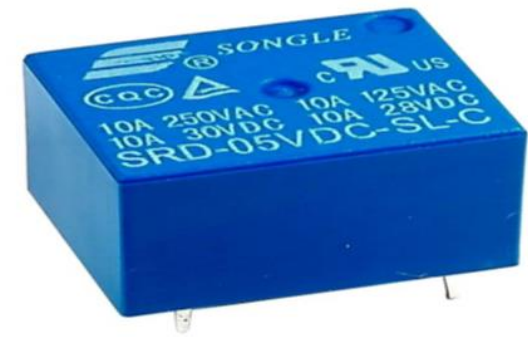

When a relay contact is Normally Closed, there is a closed contact when the relay is not energized. In either case, applying electrical current to the contacts will change their state.

\section{Light Emitting Diode (LED):}

LED i.e. light emitting diode is a semiconductor device which emits light when an electric current is passed through it. The semiconductor material used to manufacture LED are:

- Indium Gallium nitride (InGaN)

- Aluminum gallium indium phosphide (AlGaInP)

- $\quad$ Aluminum gallium arsenide (AlGaAs)

- Gallium phosphide (GaP)

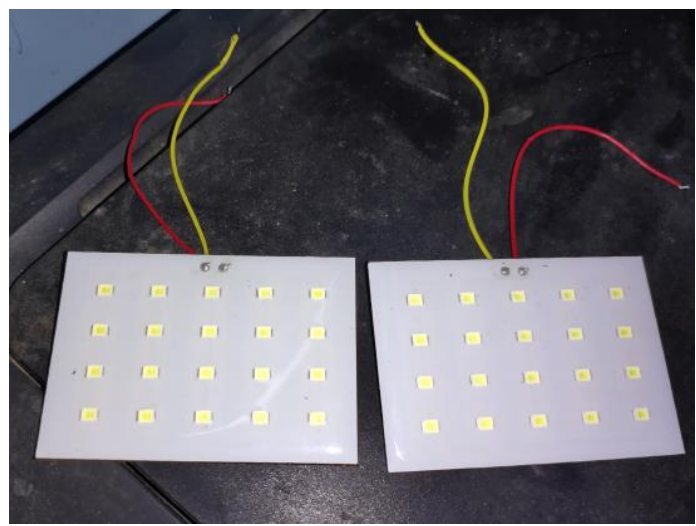

LEDs used in this project are programmed with the arduino software. These will glow according to the solar status.

The software requirement is presented in next section.

\section{SOFTWARE REQUIREMENT}

\section{PHP (Hypertext Preprocessor):}

PHP is a popular general purpose scripting language used for developing web applications. It is a server-side scripting language. It edits the information and pull it from the database which is written in SQL.

Server-Side Script Features:

- Open Source

- Interpreted

- Real Time Access Monitoring

- Case Sensitive

- Platform Independent

The PHP code will run as a web server module. To run the PHP code, we need to install Web Server like MYSQL. There are many such web servers for running programs in PHP like XAMPP and WAMP. XAMPP server is supported in Windows and Linux whereas WAMP server is supported in Windows only. In this project, we have used XAMPP server for running the PHP program on the web server.

\section{Xampp:}

Xampp is a software which provides the MYSQL database, Apache web server, PHP and Perl all in one package. XAMPP stands for Cross-Platform (X), Apache (A), MariaDB (M), PHP (P) and Perl (P). It allows us to work on a local server and test the local copies of the websites using PHP code and MYSQL databases. Once the XAMPP is active, we can access our local copy with a browser using an url like "http://localhost/" or "http://127.0.0.1/".

\section{MYSQL:}

MYSQL is the combination of "My", the name of co-founder Michael' Widenius's daughter, and "SQL", i.e. Structured Query Language. It is an open-source software which is used by many database-driven web applications. 


\section{EXPERIMENTAL PROTOTYPE}

The experimental prototype of the system is shown below

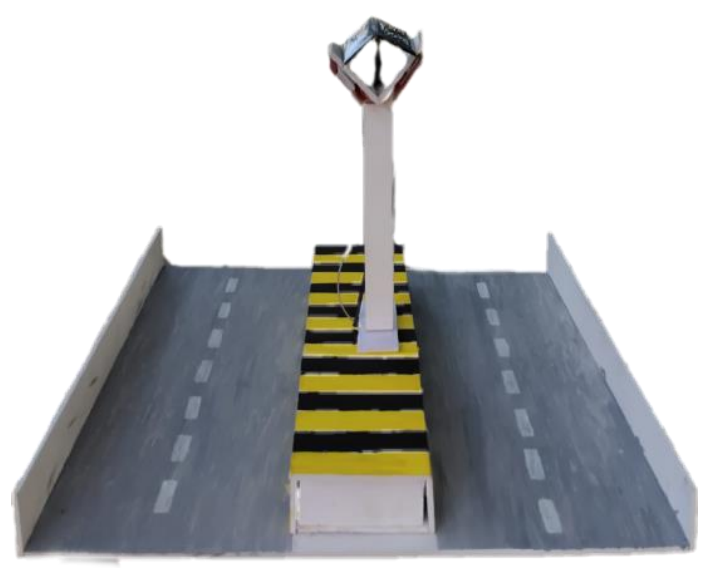

The design procedure is explained below:

The system consists of Node MCU, Wi-Fi ESP32 programmable microcontroller, Solar panel used to charge the battery. The light will turn $\mathrm{ON}$ only in night time by sensing the solar voltage. In night, the voltage of solar panel is 0 and so the LED light will Turn ON. The battery gets charged from the solar panel and battery gives power supply to the system.

The Wemos is programmed to get the data from the battery voltage and solar voltage and compare it periodically. The IP address is assigned by the hotspot to the Node MCU and we can access it from the Wi-Fi network. The system is programmed in the arduino and connected to the server via PHP programming. A tabular database is maintained which is programed in SQL to monitor the data from any time. Website is created with the help of PHP to get the access of the data in the server from anywhere. IP address is assigned to it. When we type that IP address in the web browser then we get the output link below.

The site will be consisting of the battery voltage and solar voltage with the date and time. In case, if the battery/panel got damaged or stolen or if it goes 0 volt then an SMS will be sent to the respective provided mobile number.The results are presented in next section.

\section{RESULT \& DISCUSSION}

Prospect of the project "IoT based Smart Solar Street Light Battery/Panel Fault Detection" has been designed and implemented using PHP, Mysql and Arduino Software. Figure shown below illustrates the results observed on the server.

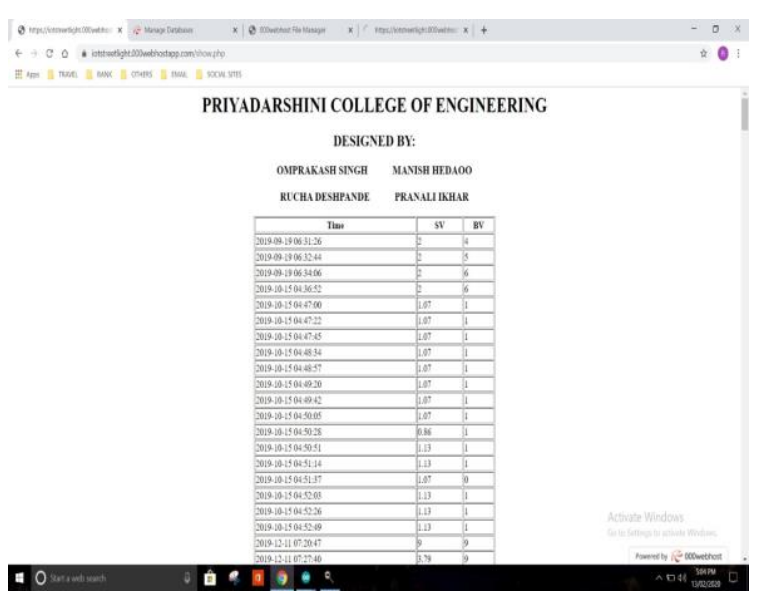

The above figure shows the monitored Solar Voltage and Battery Voltage values with respect to time on the server. Whenever the Solar Voltage or Battery Voltage values goes 0 , it will send an SMS to the registered mobile number to get to know the status of Panel and Battery.

\section{CONCLUSION}

IoT based Smart Solar Street Light Battery/Panel Fault Detection is designed using PHP and Arduino software. The monitoring scheme is to measure the equivalent voltage of Battery and Panel, by measuring it we come to know about the status of the Street light and so the fault can be judged by the voltage value and the fault point is traced and also the system sends alert message to the authorized person's mobile numbers. We can monitor the system from anywhere and anytime. This technology of Automatic Smart Street Light Battery/Panel Fault Detection is a cost effective, practical, ecofriendly and the safest way to save energy. It clearly tackles the two problems that world is facing today, saving of energy and timely maintainance by proper monitoring very efficiently.Through this project we can save energy and do effective maintenance. This work is helpful for solving the energy \& providing effective maintenance.

\section{REFERENCE:}

[1] Mohd.Saifuzzaman, Nazmun Nessa Moon, Femaz Narin Nur (Dec 2017) 'Iot Based Street Lighting And Traffic Management System', IEEE Region 10 Humanitarian Technology Conference, Vol-6(Issue 1). 
[2] K.Tamilselvan, K.S.Deepika, A.Gobinath, S.Harhini (2018) 'Iot Based Street Light Monitoring System', International Journal of Intellectual Advancements and Research in Engineering Computation, Vol-6(Issue 1).

[3] Prakash, Prabhu v, Dandu Rajendra (May 2016) 'Iot Based Intelligent Street Lighting System for Smart City', International Journal of Innovative Research in Science, Engineering and Technology, Vol-5(Issue 5), pp. 5.

[4] Shubham R. Shukla, Vinay D. Kadu, Pranav P. Ghormade (2017) 'Electrical Hybrid Street Light With Security and Maintenance Alert', International Journal of Engineering Development and Research, Vol-5(Issue 1), pp. 1-2.

[5] Faisal Amin, Al zarooni, Dr.Ahmed Osman (Jan 2017) 'Solar Powered LED Street Lighting
System', International Journal of Scientific \& Engineering Research, Vol-8(Issue 1).

[6] Snehal Bhosale, Komal Gaware, Pradnya Phalke (May 2017) 'Iot Based dynamic Control of Street Lights For Smart City', International Research Journal of Engineering and Technology, Vol-4(Issue 5), pp. 1-3.

[7] Prof. Bhargav B Patel, Prajapati Kinjal, Gupta Vinnie, Patel Devl (May 2015) 'Solar Smart LED Street Lighting System', International Journal of Advanced Engineering Research and Development, Vol-2(Issue 5), pp. 2-5.

[8] Ms. M. Kokilavani, Dr. A. Malathi (Nov 2017) 'Smart Street Lighting System Using Iot', International Journal of Advanced Research in Applied Science and Technology , Vol3(No.11), pp. 1-4. 